\title{
STEP: Conservation Based on Science
}

\section{Shiang-Lin Huang*}

Department of Environmental Biology and Fishery Science, National Taiwan Ocean University, Keelung, Taiwan

Conservation of biodiversity and endangered species has now become a global and multi-disciplinary synthesis over the scientific, politic, economic and social issues. Extinction of threatened species is not only a biological disaster but also causes economic and cultural loss. By 2008 approximate 3000 marine species, including shark, rays, groupers, reef-building corals, marine mammals and marine turtles are assessed to be VU (Vulnerable), EN (Endangered) or CR (Critically Endangered) [1]. Despite iterated calls of necessary actions to prevent or mitigate any threat that is possible to endanger the survival of species and biodiversity integrity, the precautionary principle, the conservation of biodiversity and endangered species is still frequently frustrated by rapid and uncompensated environment development, low and insufficient awareness, short of funding and, most fundamentally, lack or scarcity of quantitative baselines.

Ideally, precautionary conservation does not rely on sophisticated and precise data; however, quantitative baselines from strictly-designed scientific studies are essential for the implementation of conservation to be effective. The awareness of biodiversity and endangered species conservation seldom really receive sufficient attention until essential baselines have been constructed. Conservation managements under the lack or scarcity of quantitative baselines, even applying precautionary principle, are often qualitative and abstractive but less efficient. One of the classical examples comes from the protected area design for the threatened cetacean species. In Yangtze there are now seven in situ reserves for protecting the critically endangered freshwater cetaceans, the baiji (Lipotes vexillifer) and Yangtze finless porpoise (Neophocaena asiaeorientalis asiaeorientalis), in the Yangtze River [2-4]. Neither the site nor the size of reserves, however, provides sufficient protection for the cetaceans [4]. In southeast China coast the design (size and site determination) of many reserves for the threatened Indo-Pacific humpback dolphins (Sousa chinensis) does not actually cope with the distribution patchiness of humpback dolphins. These enacted reserves can not effectively neutralize or mitigate anthropogenic impacts, but worse, sometimes escalate the population fragmentary due to continuous habitat degradation and deterioration outside the reserves, like the situation happening in the humpback dolphins off western Taiwan coast [5-7].

The baselines essential for sound conservation management can be generally summarized into four major compartments: The Endangered Species or Focal Sites (S), Threats Identification and Assessment (T), Quantitative Evaluation on Population Viability under Impacts (E) And Finally the Policy Planning for Conservation Actions (P), or STEP. The validated adoption of surrogate species and/or focal sites with characteristic biodiversity can facilitate to attract conservation awareness (e.g. the flagship species), indicate the quality and/or integrity of featured ecosystem (indicator species) and/or provide protective umbrella to sympatric organisms (umbrella species) [8]. Census for the species status, including the distribution pattern and abundance, will be needed for the design of sound protected areas. Impacts threatening the survival of species and integrity of biodiversity usually come from multi-sources, such as the threats endangering the survival of Yangtze finless porpoise [2]. Distinguishing the types of threats and quantifying the extents of threats can be helpful to define a tolerable threshold for mitigation or prohibition actions. Quantitative evaluation, including trend analysis, risk and impact assessments for the endangered species and biodiversity integrity, can be the central part of informed conservation tactics [9]. Adopting the thresholds in the IUCN Red List Categories and Criteria Version 3.1 [9] as a proxy, the viability of an endangered species/population (rate of decline, probability of extinction and number of adults), and hence the extent of anthropogenic impacts on the survival of endangered species can be quantified by the use of quantitative modeling exercises $[3,10$ 13]. Sound conservation planning can be designed and dynamically adjusted based on baselines from above studies.

Effective conservation actions need direct feedbacks from but do not and should not wait for the precise scientific data. Conservation of endangered species and biodiversity integrity can often be obstructed by the lack, scarcity and/or even messiness of essential baselines, including distribution pattern, abundance, types, frequency and strengths of threats, population viability and biodiversity integrity. An integrative perspective, STEP (Species and Focal Sites, Threats Identification and Quantification, Evaluation of Population Viability under Impacts and Policy/Planning Made according To Feedbacks from Baseline Studies), could help to figure and prioritize the effective conservation plans.

\section{References}

1. Polidoro BA, Livingstone SR, Carpenter KE, Hutchinson B, Mast RB, et al (2009) Status of the World's Marine Species. In; Wildlife in a Changing World An Analysis of the 2008 IUCN Red List of Threatened Species. Editors Vié JC, HiltonTaylor C, Stuart SN. Gland, Switzerland: IUCN.

2. Wang D (2009) Population Status, Threats and Conservation of the Yangtze Finless Porpoise. Chinese Science Bulletin 54: 3473-3484.

3. Mei Z, Huang SL, Hao Y, Turvey ST, Gong W, et al. (2012) Accelerating population decline of Yangtze finless porpoise (Neophocaena asiaeorientalis asiaeorientalis). Biol Conserv 153: 192-200.

4. Zhao X, Wang D, Turvey ST, Taylor B, Akamatsu T (2013) Distribution Patterns of Yangtze Finless Porpoises in The Yangtze River: Implications For Reserve Management. Animal Conservation 16: 509-518.

5. Chou LS, Lee JD (2010) Habitat Hotspot of Humpback Dolphin, Sousa chinensis, and Master Planning for Conservation Management (in Chinese) Forestry Bureau, Council of Agriculture, Executive Yuan, Taiwan.

6. Chou LS, Lee JD, Kao CC, Chuang CT, Chen CF, et al. (2011) Population Ecology, Critical Habitat and Master Planning for Marine Mammal Protected Area of Indo-Pacific Humpback Dolphin, Sousa chinensis (in Chinese). Forestry Bureau, Council of Agriculture, Executive Yuan, Taipei, Taiwan.

7. Huang SL, Karczmarski L, Keith M, Chang WL (2013) Long-term habitat

${ }^{*}$ Corresponding author: Shiang-Lin Huang, Department of Environmental Biology and Fishery Science, National Taiwan Ocean University, Keelung, Taiwan, Tel: +886-920-093-114; E-mail: shianglinhuang@gmail.com, slhuang@mail.ntou.edu.tw

Received December 06, 2013; Accepted December 06, 2013; Published December 10, 2013

Citation: Huang SL (2013) STEP: Conservation Based on Science. J Biodivers Endanger Species 2: e109. doi:10.4172/2332-2543.1000e109

Copyright: @ 2013 Huang SL. This is an open-access article distributed under the terms of the Creative Commons Attribution License, which permits unrestricted use, distribution, and reproduction in any medium, provided the original author and source are credited. 
degradation from land reclamation: its consequence on coastal cetacean distribution. The International Conference on Challenges in Aquatic Sciences. National Taiwan Ocean University, Keelug, Taiwan.

8. Caro T (2010) Conservation by Proxy: Indicator, Umbrella, Keystone, Flagship and Other Surrogate Species. Island Press.

9. IUCN (2001) Red List Categories and Criteria version 3.1 IUCN Species Survival Commission. IUCN, Gland, Switzerland and Cambridge, UK.

10. Lacy RC (1993) VORTEX: A Computer Simulation Model for Population Viability Analysis. Wildlife Res 20: 45-65
11. Currey RJC, Dawson SM, Slooten E (2009) An Approach for Regional Threat Assessment under IUCN Red List Criteria that is Robust to Uncertainty: The Fiordland Bottlenose Dolphins are Critically Endangered. Biol Conserv 142: 1570-1579.

12. Huang SL, Hao Y, Mei Z, Turvey ST, Wang D (2012) Common Pattern of Population Decline for Freshwater Cetacean Species in Deteriorating Habitats. Freshwater Biol 57: 1266-1276.

13. Huang SL, Karczmarski L, Chen J, Zhou R, Lin W, et al. (2012) Demography and Population Trends of the Largest Population of Indo-Pacific Humpback Dolphins. Biol Conserv 147: 234-242. 